Table 2. AVerage Perchntage Regcoveriks of DreldoriN FroM SUccessive LaYkRS OF UGANDA MUD BLOCKS

\begin{tabular}{|c|c|c|c|c|c|}
\hline \multirow{2}{*}{$\begin{array}{l}\text { Relative } \\
\text { humidity } \\
\text { (per cent) }\end{array}$} & \multirow{2}{*}{$\begin{array}{c}\text { Layer } \\
\text { No. }\end{array}$} & \multirow{2}{*}{$\begin{array}{l}\text { Weight } \\
\text { of layer } \\
\text { (gm.) }\end{array}$} & \multicolumn{3}{|c|}{ Time after spraying } \\
\hline & & & $1 \mathrm{hr}$. & 4 days & 13 days \\
\hline 10 & $\begin{array}{l}1 \\
2 \\
3 \\
4 \\
5\end{array}$ & $\begin{array}{l}0 \cdot 25 \\
4 \cdot 0 \\
4 \cdot 0 \\
4 \cdot 0 \\
4 \cdot 0\end{array}$ & $\begin{array}{r}32 \\
8 \\
0 \\
-- \\
--\end{array}$ & $\begin{array}{r}69 \\
31 \\
0 \\
- \\
-\end{array}$ & $\begin{array}{r}52 \\
48 \\
0 \\
0 \\
0\end{array}$ \\
\hline 50 & $\begin{array}{l}1 \\
2 \\
3 \\
4 \\
5\end{array}$ & $\begin{array}{l}0 \cdot 25 \\
4 \cdot 0 \\
4 \cdot 0 \\
4 \cdot 0 \\
4 \cdot 0\end{array}$ & $\begin{array}{r}92 \\
8 \\
0 \\
- \\
\end{array}$ & $\begin{array}{r}17 \\
79 \\
4 \\
0 \\
-\end{array}$ & $\begin{array}{r}10 \\
67 \\
20 \\
3 \\
0\end{array}$ \\
\hline 90 & $\begin{array}{l}1 \\
2 \\
3 \\
4 \\
5 \\
6 \\
7\end{array}$ & $\begin{array}{l}0 \cdot 25 \\
4 \cdot 0 \\
4 \cdot 0 \\
4 \cdot 0 \\
4 \cdot 0 \\
4 \cdot 0 \\
8 \cdot 0\end{array}$ & $\begin{array}{r}92 \\
8 \\
0 \\
- \\
- \\
-\end{array}$ & $\begin{array}{l}16 \\
37 \\
27 \\
20 \\
- \\
-\end{array}$ & $\begin{array}{r}6 \\
23 \\
20 \\
15 \\
12 \\
10 \\
14\end{array}$ \\
\hline
\end{tabular}

concentration, however, an increase in humidity would give higher kills, and a decrease lower kills. The enhanced kill at high humidities can more than compensate for decreases in concentration so that kills would remain high even during extended periods of high humidity.

We explain these results on the basis of competition between the water and the insecticides. Water appears to be adsorbed preferentially to the insecticide and the increased amounts which are present in soils at high humidities have two effects. The initial disappearance of the insecticide from solid particles lying on the surface is retarded because water molecules already occupy a large proportion of the 'active' surface of the soil and cannot be displaced. Once the insecticide is adsorbed, however, the same preferential adsorption of water results in an increased mobility of the insecticide molecules and therefore an enhanced rate of diffusion farther into the soil or, alternatively, an enhanced rate of diffusion on to and into an insect resting on the soil.

The laboratory findings therefore provide an explanation for the results obtained in the field by Burnett and by Bordas and Navarro where mos. quitoes enter huts and can be killed by contact or fumigant action on treated walls.

'Colonial Insecticides Research,

F. BARLOW

A. B. Hadaway

Porton.

Sept. 17.

"Bordas, E., and Navarro, L., WHO (Malaria), 125 (Geneva, 1955).

Burnett, G., Nature, 177, 663 (1956)

s Hadaway, A. B., and Barlow, F., Bull. Ent. Res., 43, 281 (1952)

${ }^{4}$ Barlow, F., and Hadaway, A. B., Bull. Ent. Res., 46, 547 (1955).

\section{Reactions to Shading in the Sea Urchin, Psammechinus miliaris (Gmelin)}

Is this urchin, podia withdraw in response to sudden shading. When the aboral hemisphere was subjected to an illumination of 250 metre-candles from a tungsten filament lamp, according to the individual, a 3-20 per cent decrease in intensity proved a minimal stimulus. Most of the podia responded simultaneously when the light was relatively bright ; but when dim, or when the shadow was faint, many fewer responded and then at different times.
By using calibrated neutral filters it was found that the interval between instantaneous shading and the appearance of a clearly visible response varied inversely with the intensity of illumination and the degree of intensity change.

In successive experiments with an illumination of more than 100 metre-candles, in response to a 20 per cent decrease, this interval was approximately constant for each individual, but at 5-20 metre-candles it varied considerably. Despite such variations, there was sometimes an indication of adjustment, in that this period decreased in successive experiments under the same conditions.

Urchins must be exposed to light for a certain length of time before they react to shading, the duration varying inversely with the light intensity. Different individuals required $0 \cdot 5-2 \cdot 0 \mathrm{~min}$. at 60 metre-candles, and 3-22 min. at 6 metre-candles. The response thus depends, in part at least, on photochemical reactions.

The relative effectiveness of exposure to light in regions of the spectrum between 400 and $560 \mathrm{m \mu}$ and between 620 and $700 \mathrm{~m} \mu$ was determined by means of four coloured filters with known transmission, and a light source of known colour temperature. For this response, using the relative amount of light energy transmitted by the filters as a basis for comparison, the animal appeared most sensitive between 440 and $560 \mathrm{~m} \mu$.

The work was done at the Plymouth Laboratory of the Marine Biological Association, and a full account will be published later.

\section{N. Mriloti}

M. YoshIDA

Department of Zoology, Bedford College

(University of London), Regent's Park, London, N.W.I. Sept. 27.

\section{Plastochron Determination in Ranunculus using Carbon-14 Dioxide}

IETERMINÁrion of the plastochron, or time interval between the formation of successive leaf primordia, suffers from the difficulty of establishing the age of a primordium at any particular stage of development. An autoradiographic technique has been successfully used for obtaining an estimate of the plastochron of Ranunculus by indirect means.

'The technique utilizes differences in amount of active material taken up by young leaves in different stages of development following administration of carbon-14 dioxide to one of the fully mature leaves. 'Two doses, at an interval of several weeks, are followed by a period in which the adjacent young leaves are allowed to grow to maturity. The leaves are then dried and exposed for two weeks to X-ray film, allowing the relative activity of successive leaves to be determined. Differences in uptake become evident as peaks of activity separated by a gap of leaves with lower activity. From the number of leaves between the peaks, the average rate of formation of successive leaf primordia can be calculated.

Ten plants of Ranunculus hirtus B. and S. were grown for four months under fluorescent lighting at 500 foot-candles intensity and at a temperature of 